\title{
Factors related to musculoskeletal disorders in quality control palm workers at palm purchasing establishments in Sichon District, Nakhon Si Thammarat, Thailand
}

\author{
Jittaporn Mongkonkansai ${ }^{1, A-D \oplus}$, Chamnong Thanapop ${ }^{1, E-F}{ }^{\oplus}$, Uraiwan Madardam ${ }^{1, E-F} \oplus$, \\ Adulropa Cheka ${ }^{1, \mathrm{~B}-\mathrm{C} \oplus}$, Aliya Epong ${ }^{1, \mathrm{~B}-\mathrm{C} \oplus}$, Arfan Arwae ${ }^{1, \mathrm{~B}-\mathrm{C} \oplus}$ \\ ${ }^{1}$ Walailak University, Nakhon Si Thammarat, Thailand \\ A - Research concept and design, B - Collection and/or assembly of data, C - Data analysis and interpretation, \\ $D$ - Writing the article, E - Critical revision of the article, F - Final approval of article
}

\begin{abstract}
Jittaporn Mongkonkansai, Chamnong Thanapop, Uraiwan Madardam, Adulropa Cheka, Aliya Epong, Arfan Arwae. Factors related to musculoskeletal disorders in quality control palm workers at palm purchasing establishments in Sichon District, Nakhon Si Thammarat, Thailand. Ann Agric Environ Med. 2020; 27(2): 207-210. doi: 10.26444/aaem/122254
\end{abstract}

\begin{abstract}
Introduction and objective. The palm quality selection process has risks of problems in ergonomics. The aim of this research is to study the factors related to musculoskeletal disorders in quality control palm workers at palm purchasing establishments in Sichon District, Nakhon Si Thammarat, Thailand.

Materials and method. A cross-sectional study was conducted with 50 workers with musculoskeletal disorders, as assessed by the Bureau of Occupational and Environmental Disease, Ministry of Public Health, Thailand. Ergonomic risk assessment was performed using the Rapid Entire Body Assessment (REBA), and the data studied with the help of descriptive statistics and chi-square analyses. All data were analyzed using SPSS version 19.

Results. The sample included $96 \%$ of males with an average age of 34.2 years (SD=11.09). The participants used pickup trucks to transport palm oil from the plantation. $72 \%$ of the workers had worked at the plantation for $4.9 \pm 4.9$ years; $54 \%$ did not work overtime. The average amount of palm oil collection for palm quality control was $23.5 \pm 11.3$ tons/day. Quality control palm workers using sidecars (28\%) were found to be moderately at risk, and those using trucks (72\%) were at a high level of risk. The prevalence of musculoskeletal disorders after one year at work was $78 \%$. The amount of palm oil controlled per day, working overtime, car type used for transport, and ergonomics risk level, were significantly related to musculoskeletal disorders in quality control palm workers ( $p$-value $<0.05$ ).

Conclusions. The results indicate a need for the top management and health-related personnel to promote occupational health and safety measures for quality control palm workers.
\end{abstract}

\section{- Keywords}

musculoskeletal disorders, quality control palm workers, palm purchasing establishments

\section{INTRODUCTION}

The palm oil industry is rapidly expanding worldwide making it the largest industry in the domain of oil and fat production from 2013 - 2018 [1, 2]. The world's palm oil production has tended to increase by $3.71 \%$ per year since the drought situation began to unravel from $2013-2017$. The worldwide demand for palm oil tends to increase by $2.99 \%$ per year, as palm oil is the cheapest plant oil compared to other plant oils. This is the reason for the increasing demands for palm oil for consumption and renewable energy. In 2018, Indonesia produced the most palm oil, followed by Malaysia. The two countries together produced $83.98 \%$ of the world's palm oil. Thailand was ranked third in the world, producing 2.70 million tons, which accounted for $3.9 \%$ of the world's total palm oil product [3]. More than 1 million workers in Malaysia and Indonesia, work in the palm oil industry [4]. In Thailand, most palm oil workers work in palm plantations located in southern Thailand.

Address for correspondence: Jittaporn Mongkonkansai, Walailak University, Thailand

E-mail: jittaporn.mo@wu.ac.th

Received: 25.02.2020; accepted: 09.05.2020; first published: 02.06.2020
Palm oil is an economic crop, the most popular in Southern Thailand, after rubber. In 2017, palm oil plantations covered an area of 4.18 million rai (1 rai $=1,600$ sq. m.) with a production of 3,048 kilograms per rai [5]. Palm oil provides by-products from all parts of the palm tree, which can be used further in products of daily consumption, such as cosmetics, soaps, candles, food products, alternative energy, etc. [6, 7]. Eighty-five percent of palm oil worldwide is used in the food industry [8]. Palm plantation in the southern region is expanding continuously because of the suitable terrain and climate. The province of Nakhon Si Thammarat has the fourth highest palm plantations in the country [9]. The Sichon District has the highest production, with $23.5 \%$ of the total produce in the province. Seventy percent of the palm oil product in Nakhon Si Thammarat province is sold to palm purchasing establishments. Palm planters prefer selling their products to palm purchasing establishments because it is convenient, close to the production site, and most palm plantations have palm oil cutting teams to trim leaves and to add fertilizer [10]. The process of purchasing palm consists of inbound weighing, quality controlling, determining the purchase price, weighing outgoing vehicles, and storage. Working on palm plantations often involves issues of unsafe 
working postures, such as bending down to lift the palm, heavy palm bunching, and using spades and various other tools for prolonged periods, which cause subsequent back and shoulder pains [11].

Studies of the palm purchasing process indicate that the quality control process from the truck into the palm plantation also has the potential to cause ergonomic problems because workers use steel to pierce the palm for quality checking, and because of the heavy weights with which they regularly deal. If workers have to work for long hours, it may potentially cause musculoskeletal disorders similar to those in the palm planters in southern Thailand. It was found that $82.5 \%$ of palm plantation workers have aches in the whole body; $54.2 \%$ and $47.5 \%$ reported pains in the shoulders and back, respectively [12]. This is consistent with the symptoms of palm planters in other countries who have intense lower back, upper back, and shoulder pains [13-15]. Considering the high ergonomic risk levels caused by such issues, work conditions should be improved immediately $[14,16,17]$. Studies in both Thailand and other countries have reported significant relationships between musculoskeletal disorders in palm planters, the process of palm cutting and harvesting, age, body mass index, smoking, arm and leg muscle strength, raising and moving items with physical force, the amount of production per day, and moderately hot weather conditions $[18,19]$.

Quality control palm workers at small palm purchasing establishments require using a posture with movement in all body parts (e.g., reaching out, twisting wrists, bending down). Research exploring the risk of working postures in workers at small palm purchasing establishments, utilizing the Rapid Entire Body Assessment (REBA) technique, is still insufficient. There has been research in Thailand and abroad on the factors related to musculoskeletal disorders in palm planters; however, these studies have focused on the process of cutting or harvesting fresh palm and have not addressed the palm quality control process at palm purchasing establishments. This preliminary survey of 50 palm industry workers identifies quality control as another process that puts workers at risk of developing musculoskeletal disorders.

\section{OBJECTIVES}

The aim of the study is to investigate the prevalence of ergonomic risk factors that may contribute to musculoskeletal problems, and to assess the risk level of ergonomics in quality control palm workers at palm purchasing establishments.

\section{MATERIALS AND METHOD}

This cross-sectional survey as approved by the human research ethics committee of Walailak University (Project No. 16-065-01). The sample comprised 50 permanent workers at small palm purchasing establishments in Sichon District, Nakhon Si Thammarat, that covers 5 sub-districts: Sichon, Thung Prang, Chalong, Sao Pao and Si Khit. The researchers collected all the data between October 2017 January 2018. The data collection tools included:

1) A questionnaire which was divided into two parts: (1) general information, and (2) musculoskeletal disorders assessment for assessing pain in various parts of the body.
The assessment form is from the Bureau of Occupational and Environmental Diseases, Department of Disease Control, Ministry of Public Health in Thailand [20], measuring the severity of symptoms in each part of the body according to four levels:

$0=$ normal;

1 = symptoms during work, but after resting, symptoms disappear;

2 = symptoms during work hours, and even after resting symptoms do not disappear;

3 = symptoms during work hours and symptoms prevent working, even after resting.

A severity rating of 2 or higher meant that the worker is considered to have musculoskeletal disorders.

The questionnaire has tool quality testing with a conformance index of 0.9 between Index of Item and Objective Congruence (IOC). The data were analyzed with the help of descriptive statistics and chi-square at 95\% confidence level.

2) The REBA ergonomic risk assessment form [21] identifies ergonomic risks of the musculoskeletal disorders caused by many factors, such as improper working posture, repeated actions, heavy lifting, use of tools or equipment not suitable for workers, etc. The assessment is an analysis of posture and body movements while the workers are at work, considering various factors, such as neck, trunk, upper arm, lower arm, wrist, work piece holding characteristics, and frequency of movements over a period of time. The assessment of risk is categorized into four levels: low, medium, high, and very high.

\section{RESULTS}

General information. The sample included $96 \%$ males with an average age of $34.2 \pm 11.09$ years. Fifty-four percent had normal body mass index; $42 \%$ had graduated from secondary school; $66 \%$ did not exercise; $72 \%$ used pickup trucks to transport palm oil from the palm plantation, and had worked at the plantation for $4.9 \pm 4.9$ years; and $54 \%$ did not work overtime. The average amount of palm oil collection for palm quality control was $23.5 \pm 11.3$ tons/day.

Ergonomic risk assessment using REBA. It was found that $28 \%$ of the quality control palm workers used sidecars and had a moderate level of risk, and $72 \%$ used trucks and had a high level of risk (Tab. 1).

Table 1. Ergonomic risk assessment using REBA

\begin{tabular}{lccc}
\hline \multirow{2}{*}{$\begin{array}{l}\text { Ergonomics risk } \\
\text { level }\end{array}$} & \multicolumn{2}{c}{ Quality control palm workers amount (Percent) } & \multirow{2}{*}{ Total } \\
\cline { 2 - 3 } & Sidecars & Trucks & \\
\hline Moderate & $14(28.0)$ & $0(0.0)$ & $14(28.0)$ \\
\hline High & $0(0.0)$ & $36(72.0)$ & $36(72.0)$ \\
\hline Total & $\mathbf{1 4 ( 2 8 . 0 )}$ & $\mathbf{3 6}(\mathbf{7 2 . 0})$ & $\mathbf{5 0 ( 1 0 0 . 0 )}$ \\
\hline
\end{tabular}

Prevalence of musculoskeletal disorders. The prevalence of developing musculoskeletal disorders after one year of work was $78 \%$ (Tab. 2).

When considering the pain at various points on both the left and right sides of the body, it was found that the five top positions of the body that incurred maximum pain were 
Table 2. Musculoskeletal disorders after 1 year

\begin{tabular}{lccc}
\hline $\begin{array}{l}\text { Car type used } \\
\text { transport }\end{array}$ & \multicolumn{2}{c}{ Musculoskeletal disorders amount (Percent) } & \multirow{2}{*}{ Total } \\
\cline { 2 - 3 } & Have symptoms & No symptoms & \\
\hline Sidecars & $8(16.0)$ & $6(12.0)$ & $14(28.0)$ \\
\hline Trucks & $31(62.0)$ & $5(38.0)$ & $36(72.0)$ \\
\hline Total & $39(78.0)$ & $11(22.0)$ & $50(100.0)$ \\
\hline
\end{tabular}

the lower right arm, upper right arm, right shoulder, lower back, and right hand, with occurrence of $76 \%, 76 \%, 74 \%$, $74 \%$, and $70 \%$, respectively. For level 3, where symptoms occurred during work and did not disappear upon rest, the pains were located in the upper right arm, lower right arm, and lower back.

Factors related to musculoskeletal disorders. Factors significantly related to musculoskeletal disorders in quality control palm workers are the amount of palm oil collected for control per day $(p=0.036)$, working overtime $(p=0.044)$, vehicle type used for transport $(p=0.026)$, and ergonomic risk level $(\mathrm{p}=0.026)($ Tab. 3).

Table 3. Factors related to musculoskeletal disorders in quality control palm workers $(n=50)$.

\begin{tabular}{|c|c|c|c|}
\hline \multirow{2}{*}{ General information } & \multicolumn{2}{|c|}{ Musculoskeletal disorders } & \multirow[t]{2}{*}{$\mathrm{p}$-value } \\
\hline & No symptoms & Have symptoms & \\
\hline Gender & & & 0.443 \\
\hline Male & 11 & 37 & \\
\hline Female & 0 & 2 & \\
\hline Age (years) & & & 0.495 \\
\hline$<40$ & 8 & 24 & \\
\hline$\geq 40$ & 3 & 15 & \\
\hline BMI & & & 0.668 \\
\hline Abnormal & 4 & 17 & \\
\hline Normal & 7 & 22 & \\
\hline Education & & & 0.609 \\
\hline Lower secondary school & 9 & 29 & \\
\hline Higher secondary school & 2 & 10 & \\
\hline Exercise & & & 0.851 \\
\hline No & 7 & 26 & \\
\hline Yes & 4 & 13 & \\
\hline Working experience(years) & & & 0.407 \\
\hline$<3$ & 3 & 16 & \\
\hline$\geq 3$ & 8 & 23 & \\
\hline $\begin{array}{l}\text { Amount of palm oil collected } \\
\text { for control per day }\end{array}$ & & & $0.036^{*}$ \\
\hline$\leq 20$ Ton/day & 9 & 18 & \\
\hline >20 Ton/day & 2 & 21 & \\
\hline Working overtime & & & $0.044^{*}$ \\
\hline No & 3 & 24 & \\
\hline Yes & 8 & 15 & \\
\hline Car type used transport & & & $0.026^{*}$ \\
\hline Sidecar & 6 & 8 & \\
\hline Truck & 5 & 31 & \\
\hline Risk Level & & & $0.026^{*}$ \\
\hline Medium & 6 & 8 & \\
\hline High & 5 & 31 & \\
\hline
\end{tabular}

* Statistical significance at $\mathrm{p}<0.05$.

\section{DISCUSSION}

The objective of this study was to investigate factors related to musculoskeletal disorders in quality control palm workers at palm purchasing establishments in Sichon District, Nakhon Si Thammarat in Thailand. The amount of palm quality controlling per day, working overtime, vehicle type used for transport, and ergonomic risk levels were found to be significantly related to musculoskeletal disorders in quality control palm workers. The average daily quality controlling amount was $23.5 \pm 11.3$ tons/day, and each load which weighed more than 10 kilograms, regularly resulted in a risk of musculoskeletal disorders, which is consistent with a previous study by Akkhisuwan et al., where it was found that the weight-bearing of palm brunches weighing 10 kilograms or more may have an effect on musculoskeletal disorders [12]. A study by Pinzke and Lavesson reported that using a conveyor belt instead of carrying a heavy box for the harvested vegetables reduced bending and the risk of musculoskeletal disorders [22]. $\mathrm{Ng}$ et al., found that overtime working increased the risk of neck disorders by 2.9 times, indicating the increased work period as a major risk factor for musculoskeletal disorders [14,23]. For the type of vehicle used for palm transportation, it was found that quality control palm workers using trucks incurred more pains and had a higher risk of ergonomics than the quality control palm workers using sidecars. A likely reason for this could be that trucks allow the transportation of large quantities of palm, and the amount of palm in the truck is often higher than the eye level of the quality control palm worker. Consequently, the arms and shoulders of the workers have to be raised all the time, and they often also have to twist their bodies. Thus, these workers may be at a higher risk for musculoskeletal disorders related injuries than those using sidecars in palm quality controlling.

The risk level of quality control palm workers was found to be moderate or high, which is consistent with the findings of Deros et al., and Nawi et al., who found that palm planters have a high to very high ergonomic risk for musculoskeletal disorders $[13,24]$. After one year, it was found that $78 \%$ of the workers had pain in the body, with the highest pain located in the lower right arm, upper right arm and right shoulder, lower back, and right hand, which is consistent with the findings of other studies in Thailand [25]. For example, Rongthong et al., found that the prevalence of musculoskeletal disorders in palm planters is in the lower back, upper arm or shoulder, and hips or thighs. Outside Thailand, $\mathrm{Ng}$ et al., found that the position of the musculoskeletal disorders in palm planters in the harvesting process affected areas including the neck, upper back, lower back, arms, and hands, and particularly the lower back [26]. Many studies conducted abroad have reported that most problems in the lower back occur due to posture $[14,18,27,28]$. Assessments have identified the movement of arms and shoulders beyond 90 degrees, twisting the body and swinging the arms in the range of 90-180 degrees, and repeated movements of the body more than 4 times/minute as risk factors for musculoskeletal disorders [23].

In 2016, common labourers with injuries or accidents at work and requiring a visit to the hospital for treatment amounted to 1.5 hundred thousand people, or $4.4 \%$ of the number of all people who visited hospitals for treatment [29]. Quality control palm workers are considered as important common laborers and are becoming the locus of current health problems. If relevant authorities do not address this issue, it will affect Thailand's health management in the long term. 


\section{CONCLUSIONS}

Quality control palm workers are at a medium to high risk level of ergonomics. Most of them have musculoskeletal disorders in around one year of work. The factors significantly related to musculoskeletal disorders in these workers are the amount of palm quality controlled per day, working overtime, vehicle type used for transport, and ergonomic risk levels.

\section{Suggestions for operations}

1. The owners of palm purchasing establishments should have occupational health and safety measures in place in order to reduce the risk of musculoskeletal disorders. These measures should include limiting the quantity of palm for daily quality control, determining a suitable rest period, reducing overtime working, providing different vehicle types for palm quality controlling, training for appropriate use of operation manual equipment., modification of the work area, etc.

2. Occupational health nurses, in collaboration with academics and public health officials in the area, should be trained to cooperate with workers to improve their awareness about safety and health.

3. Occupational health nurses should work as health consultants for palm establishment owners and related parties, including other people involved in health care, to stimulate the development of new health care programs for the workers.

4. Primary care agencies should more pro-actively focus on providing occupational health services which consist of activities such as education and exploration of career, assessing health risks for each occupational group, surveillance of occupational diseases and occupational injuries, and providing health promotion and disease prevention activities.

\section{Acknowledgements}

The study was partially supported by Walailak University, Thailand.

\section{REFERENCES}

1. Shawal FNS, Guan NY, Mohd SNDH, How V, Tamrin SBM. Knowledge, attitude, and perception of risk management of steam boilers among workers in palm oil mills. Work. 2018; 60: 153-62. doi: 10.3233/wor182725

2. Cheng HT. Key Sustainability issues in the palm oil sector. A discussion paper for multi-stakeholders consultations (commissioned by the World Bank Group). International Finance Corporation, Washington DC, USA, 2010.

3. Office of Agricultural Economics. Sthānkār sinkhā kestr thī sảkhạy læa næwnôm pī 2562. [Important agricultural products and trends in 2019] [Internet]. Available at http://www.oae.go.th/assets/portals/1/ files/jounal/2562/agri_situation2562.pdf (access:2019.10.25).

4. Myzabella N, Fritschi L, Merdith N, Zaemey SE, Chih HJ, Reid A. Occupational health and safety in the palm oil industry: A systematic review. Int J Occup Environ Med. 2019; 10: 159-173. doi: 10.15171/ ijoem.2019.1576

5. Office of Agricultural Economics. Statistics of palm oil. Available from: http://www.oae.go.th/assets/portals/1/files/jounal/2562/agri_ situation2562.pdf (access: 2018.10.20).

6. Agricultural research development Agency. Use of oil palm. 2009. Available from: http://www.arda.or.th/kasetinfo/south/palm/used/0103.php. (access:2018.10.20).

7. Phitthayaphinant P, Nissapa A, Somboonsuke B, Eksomtramage T. An equation of oil palm plantation areas in Thailand. KKU Res. J. 2012; 11(1): 66-76.
8. May CY, Nesaretnam K. Research advancements in palm oil nutrition. Eur J Lipid Sci Technol. 2014 Oct; 116(10): 1301-1315. doi: 10.1002/ ejlt. 201400076

9. Office of Agricultural Economics. Satistics of oil palm. Available from: http://www.oae.go.th/assets/portals/1/files/forecast/situation/8S PL.pdf. (access:2018.10.20).

10. Office of Agricultural Economics. Kār wi kherāah dān ers bkic sinkhāa kestr thī sảkhạy: Cạnghwạd nkhrrīhrrmrāch [Important agricultural product economic analysis: Nakhon Si Thammarat province]. Available from: https://drive.google.com/file/d/1K3BIzIkoXX5v6ZBBBNMW8x YP5Y0TfWzA/view. (access: 2019.12.25).

11. Office of Agricultural Economics. Occupational health and safety for oil plam smallholders and workers. Available from: https://www.rspo. org/file/OHS.pdf. (access:2018.10.28).

12. Akkeesuwan A, Saejiw N, Thanapop C, Mahaboon J. Injury and musculoskeletal disorder among the palm plantation farmer Sinpun Sub-District, Khao Phanom District, Krabi province. J Saf Health. 2015; 29(8): 48-58.

13. Deros BM, Ali MH, Mohamad D, Daruis DDI. Ergonomic risk assessment on oil palm industry workers. Iran J Public Health. 2016; 45(Supple1): 44-1.

14. Ng YG, Mohd Tamrin SB, Mohd Yusoff IS, Hashim Z, Deros BMD, Abu Bakar S, et al. Risk factors of musculoskeletal disorders among oil palm fruit harvesters during early harvesting stage. Ann Agric Environ Med. 2015; 22(2): 286-292. doi:10.5604/12321966.1152101

15. Mohd Nawi NS, Md Deros B, Ab Rahman MN, Sukadarin EH, Nordin N. Malaysian oil palm workers are in pain: Hazards identification and ergonomics related problems. Malays J Public Health Med. 2016; 1(Specialissue1): 1-8.

16. Mohd Ysoff IS, Mohd Tamrin SB, Mat Said A, Guan NG Y, Ippei M. Oil palm workers: Designing ergonomics harvesting tool using user centered design approach to reducing awkward body posture by catia simulation. Iran J Public Health 2014; 43: 72-80.

17. Nur Syazwani MN, Md Deros B, Ab Rahman MN, Ezrin Hani S, Norani N, Shamsul Bahri MT, et al. Ergonomic risk assessment of manual handling tools by oil palm collectors and loaders. Malays J Public Health Med. 2016; 16: 56-60.

18. Ng YG, Tamrin SB, Yik WM, Yusoff IS, Mori I. The prevalence of musculoskeletal disorder and association with productivity loss: A preliminary study among labour intensive manual harvesting activities in oil palm plantation. Ind Health. $2014 ; 52$ : 78-85. doi: $10.2486 /$ indhealth.2013-0017.

19. Tassanawong P, Chanthorn W, Rakprasit J. Prevalence and factors associated with musculoskeletal disorders among tea farmers, Thoet Thai Subdistrict, Mae Fa Luang District, Chiang Rai Province. Srinagarind Med J. 2018; 33(5): 457-464.

20. Department of Disease Control, Ministry of Public Health, Thailand. Musculoskeletal disorders assessment form. Available from: http:// odpc5.ddc.moph.go.th/ (access: 2020.04.20).

21. Hignett S, McAtamney L. Rapid Entire Body Assessment (REBA). Appl Ergonom. 2000; 31(2): 201-5.

22. Pinzke S, Lavesson L. Ergonomic conditions in manual harvesting in Swedish outdoor cultivation. Ann Agric Environ Med. 2018; 25(3): 481-487. doi:10.26444/aaem/93334

23. Sasitorn Taptagaporn. Occupationnal Ergonomics and Safety. Thammasat University, Bangkok, Thailand, 2016.

24. Nawi NSM, Md Deros B, Norani N. Assessment of oil palm fresh fruit bunches harvesters working postures using Reba. Adv Eng Forum. 2013; 10: 122-7. doi: 10.4028/www.scientific.net/aef.10.122

25. Rongthong M, Kongtawelert A, Sujirarat D, Bhuanantanondh P. Prevalence of Musculoskeletal Disorders among new oil palm harvesting workers. HCU J of Health Sci. 2019; 23(1): 75-92.

26. Ng YG, Shamsul Bahri MT, Irwan Syah MY, Mori I, Hashim Z. Ergonomics observation: harvesting tasks at oil palm plantation. J Occup Health. 2013; 55: 405-414. doi: 10.1539/joh.13-0017-fs

27. Henry LJ, Jafarzadeh Esfehani A, Ramli A, Myzabella N, Fritschi L, et al. Patterns of work-related musculoskeletal disorders among workers in palm plantation occupation. Asia Pac J Public Health. 2015; 27: 1785-1792. doi: 10.1177/1010539513475657

28. Sukadarin EH, Deros BM, Nawi NSM, Ghani JA, Ismail AR, Zakaria J. Back pain and the observed factors among oil palm workers. Int J Eng Tech Sci. 2016; 5: 70-78. doi: http://dx.doi.org/10.15282/ ijets.5.2016.1.9.1048

29. Chantaramanee N. Risks of health and safety in work of informal agricultural workers, Amphoe Phu Kamyao, Phayao province. EAU Herit J Sci Tech. 2017; 11(3): 112-123. 